\title{
Mission Profile Based Optimization of a Synchronous-Buck DC-DC Converter for a Wearable Power System
}

\author{
M. Vasić1 , S. D. Round ${ }^{2}$, J. Biela ${ }^{2}$, J. W. Kolar ${ }^{2}$ \\ ${ }^{1}$ Universidad Politécnica de Madrid (UPM), Centro de Electrónica Industrial (CEI) \\ José Gutiérrez Abascal 2, 28006 Madrid, Spain \\ ${ }^{2}$ ETH Zurich, Physikstrasse 3, 8092 Zurich, Switzerland \\ miroslav.vasic@upm.es
}

\begin{abstract}
A Wearable Power System (WPS) is a portable fuel-to-electrical energy converter that is carried on the body and is able to supply an average of $20 \mathrm{~W}$ for 4 days and has a total weight of less than $4 \mathrm{~kg}$. Due to limited total weight of the system, each system part must have the highest efficiency to weight ratio. This paper presents the optimization of a synchronous buck DCDC converter that is used to regulate the variable power source to a constant $14 \mathrm{~V}_{\mathrm{DC}}$ for the load. Higher switching frequency leads to smaller components and low weight, but at the same time, to higher losses that are compensated through additional fuel weight. If low switching frequency is applied, the weight of the converter will increase due to a larger inductor, but the power losses will be lower. Therefore, an optimal switching frequency should exist that results in the total weight of the DC-DC converter and additional fuel being a minimum. The paper first explains the proposed solution for WPS, the load pattern that is used to test the system and then the algorithm that decides on the number of converters to be used and how to find the optimal switching frequency. Additionally, two prototypes have been constructed. First prototype has nominal power of $20 \mathrm{~W}$ and is used in the analysis regarding the optimal number of converters. The second one has rated power of $200 \mathrm{~W}$ and it is built to support the conclusions based on the optimization process.
\end{abstract}

\section{INTRODUCTION}

In 2008, the US Department of Defense (DOD) organized a $\$ 1$ million first prize competition to develop a new wearable power system for their soldiers [1]. In the future, these soldiers will carry new portable equipment such as video and communication systems that have high peak power demands. The aim of the US DOD was to get competing teams to develop a range of new technologies so that a wearable power system can supply $1920 \mathrm{Wh}$ of energy over 4 days (to provide an average load of $20 \mathrm{~W}$ ) and has a total system weight of less than $4 \mathrm{~kg}$.

The current energy source for soldiers is based on batteries, which are heavy and offer no fast recharging capability in the field. A solution to this could be the use of fuel cells, due to their high specific energy, high efficiency and improved environmental performance and they could be incorporated into rechargeable energy storage system. However, besides all these advantages, fuel cells need a large amount of hydrogen, which is difficult to store in lightweight fashion, so they are not promising candidates to meet construction requirements [2]. An alternative is to use liquid fuels, such as mixtures methanol/oil and gasoline/oil mixtures, since they have a high heating value. Therefore, a WPS based on a combination of a small internal combustion engine (ICE) and a battery pack has been investigated and a prototype has been built.
The block diagram of the ICE based wearable power system is shown in Figure 1. In this solution, the majority of the energy is stored in a liquid gasoline fuel. The energy is extracted from the fuel as mechanical energy by a small-scale, single-cylinder, 4-stroke internal combustion engine. The engine is run with a low duty cycle and has an energy conversion efficiency of less than $20 \%$. This engine in turn rotates a custom, permanent magnetic, three-phase electrical generator. This generator is an ideally suited machine for the task of electro-mechanical conversion as it has small size, low-weight and high efficiency. A power electronics converter together with the engine controller, regulates the flow of the generator's output power. A rechargeable battery is employed as a limited, intermediate energy storage element. The power provided from the generator recharges the battery and/or provides the power directly to the electrical output loads. Majority of the time the loads are supplied solely by the rechargeable battery. The competition rules require two output voltages; $28 \mathrm{~V}$ (range of 20-32 V) and $14 \mathrm{~V}$ (range of 10-16 V) [3]. The electrical output loads are supplied either directly from the $28 \mathrm{~V}$ battery or through a step-down dc-dc converter.

Four load levels, of $3 \mathrm{~W}, 20 \mathrm{~W}, 50 \mathrm{~W}$ and $200 \mathrm{~W}$, and three load types are specified [4]. The three load types are: Base Load, Communications Load and Video Feed Load, and these load types are repeated during the testing of the system. The typical load profile (Figure 1(b) for 1 day) presents the main challenge since the peak load is ten times that of the average load. Table 1 shows the details of a typical 24-hour load profile.

The $3 \mathrm{~W}$ load is applied for the longest time (78\%), while the $200 \mathrm{~W}$ load is applied for, a relatively short, $7 \%$ of the time. However, considering the amount of energy each load consumes then the $200 \mathrm{~W}$ load uses $67 \%$ of the energy while the other three load levels each consume approx $11 \%$ of the energy. The $200 \mathrm{~W}$ load, in the worst case for a video load, lasts for 5 minutes and repeats every 5 minutes for up to 1 hour. This results in an average video load power of $110 \mathrm{~W}$, which is much greater than the 4-day average of $20 \mathrm{~W}$. The output dc-dc converter that steps the battery voltage of $28 \mathrm{~V}$ down to $14 \mathrm{~V}$ must be designed according to the load profile, operate with the highest efficiency in order to minimize the additional fuel required to generate the losses and to have a minimal converter weight.

In [5] it is explained how to optimize the system regarding the fuel and battery type. This paper presents the optimization of the output synchronous-buck $(28 \mathrm{~V}-14 \mathrm{~V})$ converter [6] considering the load mission profile. 


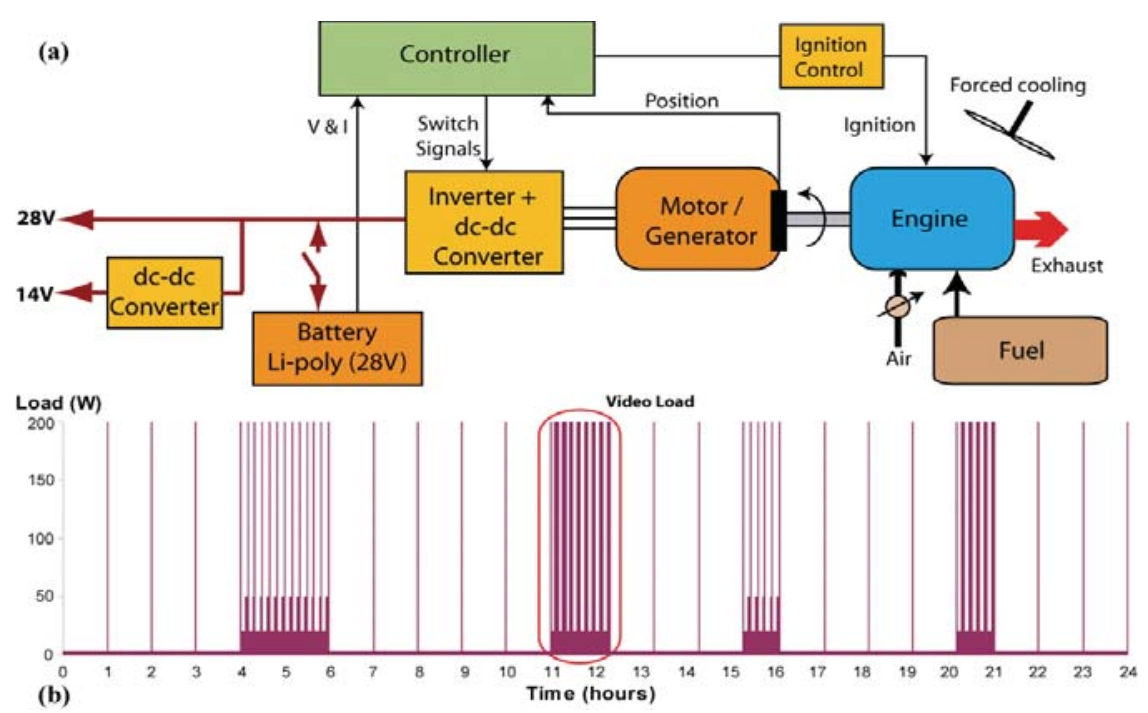

Figure 1: (a) Wearable Power System, (b) 24-hour load profile, where the high power video load is highlighted.

TABLE I

EXAMPLE OF A 24-HOUR LOAD PROFILE (BENCH TEST)

\begin{tabular}{|c|c|c|c|c|c|c|c|}
\hline Load Type & $\begin{array}{l}\text { Load } \\
\text { (W) }\end{array}$ & \begin{tabular}{|l|} 
Time \\
$(\mathrm{min})$ \\
\end{tabular} & $\begin{array}{c}\text { Repeat } \\
\text { (\# of cycles) }\end{array}$ & \begin{tabular}{|c}
$\begin{array}{c}\text { Total Time } \\
\text { (min) }\end{array}$ \\
\end{tabular} & $\begin{array}{l}\text { Energy } \\
\text { (Wmin) }\end{array}$ & \begin{tabular}{|c|} 
Average \\
(W)
\end{tabular} & \begin{tabular}{|l|} 
Time \\
(hrs)
\end{tabular} \\
\hline \multirow{2}{*}{ Base Load } & 3 & 59 & \multirow{2}{*}{4} & 236 & 708 & \multirow{2}{*}{6.3} & \multirow{2}{*}{4} \\
\hline & 200 & 1 & & 4 & 800 & & \\
\hline \multirow{3}{*}{ Communications } & 20 & 6 & \multirow{3}{*}{12} & 72 & 1440 & \multirow{3}{*}{47} & \multirow{3}{*}{2} \\
\hline & 50 & 3 & & 36 & 1800 & & \\
\hline & 200 & 1 & & 12 & 2400 & & \\
\hline \multirow{2}{*}{ Base Load } & 3 & 59 & \multirow{2}{*}{5} & 295 & 885 & \multirow{2}{*}{6.3} & \multirow{2}{*}{5} \\
\hline & 200 & 1 & & 5 & 1000 & & \\
\hline \multirow{2}{*}{ Video Feed Load } & 20 & 5 & \multirow{2}{*}{8} & 40 & 800 & \multirow{2}{*}{110} & \multirow{2}{*}{1.3} \\
\hline & 200 & 5 & & 40 & 8000 & & \\
\hline \multirow{2}{*}{ Base Load } & 3 & 59 & & 177 & 531 & \multirow{2}{*}{6.3} & \multirow{2}{*}{3} \\
\hline & 200 & 1 & 3 & 3 & 600 & & \\
\hline \multirow{3}{*}{ Communication } & 20 & 6 & \multirow{3}{*}{5} & 30 & 600 & \multirow{3}{*}{47} & \multirow{3}{*}{0.8} \\
\hline & 50 & 3 & & 15 & 750 & & \\
\hline & 200 & 1 & & 5 & 1000 & & \\
\hline \multirow{2}{*}{ Base Load } & 3 & 59 & \multirow{2}{*}{4} & 236 & 708 & \multirow{2}{*}{6.3} & \multirow{2}{*}{4} \\
\hline & 200 & 1 & & 4 & 800 & & \\
\hline \multirow{2}{*}{ Video Feed Load } & 20 & 5 & \multirow{2}{*}{5} & 25 & 500 & \multirow{2}{*}{110} & \multirow{2}{*}{0.8} \\
\hline & 200 & 5 & & 25 & 5000 & & \\
\hline \multirow{2}{*}{ Base Load } & 3 & 59 & \multirow[t]{2}{*}{3} & 177 & 531 & \multirow{2}{*}{6.3} & \multirow{2}{*}{3} \\
\hline & 200 & 1 & & 3 & 600 & & \\
\hline
\end{tabular}

One could consider using a single dc-dc converter optimized for $200 \mathrm{~W}$ operation but at the lower power levels, e.g. $20 \mathrm{~W}$, the efficiency would be lower than for a separate dc-dc converter optimized for $20 \mathrm{~W}$ operation. However, the extra converter would add to the system weight. Therefore, the additional fuel saved due to the increased efficiency must be greater than the additional converter weight. A number of questions need to be answered, such as how many converters should be used, i.e. 1, 2 or 3, and what is their power level? What is the minimal converter weight while still achieving a high efficiency and minimal fuel weight? This paper presents the analysis and optimization procedure to design the DC-DC converter. Experimental converters for 20 and $200 \mathrm{~W}$ are constructed to provide actual efficiency and weight data for the optimization procedure. Finally, the optimal dc-dc converter configuration is presented.

\section{CONVERTER OPTIMIZATION}

\section{A. NUMBER OF CONVERTERS}

The load has a wide range of output power levels and applied time intervals (Table II) and the lowest $3 \mathrm{~W}$ load is applied for the longest time. Therefore, the considered DC-DC converter system has to have a high efficiency for light loads since the lost energy must be provided by the gasoline and results in a higher system weight.

Basically, the efficiency of a DC-DC converter drops at light load due to loss components such as capacitive switching losses, gate drive or control losses, which do not decrease linearly with or are independent of output power. A possibility to increase the efficiency at light load is to connect together converter systems with lower nominal power ratings in parallel and operate different combinations for each load level [7], so that the operating point of each converter that is providing the output power is near to its nominal value.

Usually, the parallel converters are designed so that they all have the same nominal power, i.e. at full load the power is equally provided by all converters. In case of the considered mission profile, where for relatively long times a low power compared to the nominal power is required, a system design with parallel converters, which do not have the same nominal power, could result in a better system efficiency compared to a design with equal converter units. Therefore, the total energy loss is the criteria for the comparison, since it is important not only to consider the efficiency but also the time interval.

TABLE II

OUTPUT POWER LEVELS AND TIME PERIODS

\begin{tabular}{|c|c|}
\hline Duration & Power Level \\
\hline $1121 \mathrm{~min}$ & $3 \mathrm{~W}$ \\
\hline $169 \mathrm{~min}$ & $20 \mathrm{~W}$ \\
\hline $57 \mathrm{~min}$ & $50 \mathrm{~W}$ \\
\hline $93 \mathrm{~min}$ & $200 \mathrm{~W}$ \\
\hline
\end{tabular}


In order to determine the best combination of nominal power levels and operating points an optimization has been performed, which minimizes the total energy that is lost during the mission. Consequently, the quality criteria is

$$
P_{V}=\sum_{j=1}^{N_{\text {Pro }}} \sum_{i=1}^{N_{\text {Par }}} P_{L}\left(\delta_{i, j}, P_{N, i}\right)
$$

where $\delta_{i, j}$ are the operating points, $P_{N, I}$ the nominal power, $N_{\text {Par }}$ the number of parallel connected converters and $N_{\text {Pro }}$ the number of power levels of the mission profile. The values of the losses are based on experimental measurements, for a 200W and a 20W system (cf. Sec. 3), and on analytical models for interpolating the loss functions.

In Table III the numerical values for the losses, the average efficiency and the distribution of the nominal power are given. It can be seen that by optimizing the nominal power levels and the operating points more than $30 \%$ of the losses of the original system can be saved and that a system with two parallel connected converters is optimal. Increasing the number of the parallel converter results in a distribution, where the optimization algorithm sets one nominal power to zero, i.e. going back to two systems.

A similar result can be obtained by the following consideration: Let us assume that a converter, $A$, has an efficiency of $\eta_{A}$ for an output load power level $P$, where this power level is less than converter $A$ 's nominal power. Therefore, converter $A$ is operating with a reduced efficiency (i.e. a non-optimal operating point). By replacing converter $A$ with converter $B$, which is optimized for the output power $P$ and has an efficiency of $\eta_{B}$, the fuel savings due to the higher efficiency are

$$
\Delta m=\frac{P \cdot t}{L H W \cdot \eta_{E}} \cdot \frac{\eta_{B}-\eta_{A}}{\eta_{A} \cdot \eta_{B}}
$$

where $L H W$ is the heating value of the fuel $(43 \mathrm{MJ} / \mathrm{kg}$ for gasoline), $\eta_{E}$ is the efficiency of the engine and inverter (approximately 13.5\%) and $t$ is the total operating time of converter $B$. Nevertheless, the additional weight of the PCB and inductor of the new converter and decreased reliability should not be forgotten. If the additional converter $B$ has a rated power of $20 \mathrm{~W}$ and assuming a $200 \mathrm{~W}$ nominal power for converter $A$, a weight of $10 \mathrm{~g}$ for the additional $\mathrm{PCB}$, and an inductor weight of $10 \mathrm{~g}$, it would be necessary to have fuel weight savings of at least $30 \mathrm{~g}$ in order to obtain a benefit from the additional converter. Using the mission load profile, the efficiency of the combustion engine and the heating value of the fuel, the minimum efficiency of the additional converter is calculated in order to save at least $30 \mathrm{~g}$ of fuel, when the load demands $3 \mathrm{~W}$ and $50 \mathrm{~W}$. Due to the load characteristics, the minimum efficiency for the $20 \mathrm{~W}$ converter is the same as for the $3 \mathrm{~W}$ load. In Figure 2, the result of this analysis can be seen and it clearly shows that if we could make a $200 \mathrm{~W}$ converter, such that its efficiency at $50 \mathrm{~W}$ is higher than $80 \%$, and at $3 \mathrm{~W}$ and $20 \mathrm{~W}$ higher than $85 \%$, then this single converter would be the best solution for the system.
TABLE III

PERFORMANCE OF 1 TO 3 PARALLEL CONNECTED CONVERTERS

\begin{tabular}{|c|c|c|c|}
\hline $\begin{array}{c}\text { Numver of } \\
\text { converters }\end{array}$ & 1 & 2 & 3 \\
\hline Energy loss & $115 \mathrm{kWs}$ & $79.3 \mathrm{kWs}$ & $79.3 \mathrm{kWs}$ \\
\hline Efficiency & $93.6 \%$ & $95.5 \%$ & $95.5 \%$ \\
\hline $\begin{array}{c}\text { Optimal } \\
\text { power levels }\end{array}$ & $200 \mathrm{~W}$ & $\begin{array}{c}3 \mathrm{~W} / \\
197 \mathrm{~W}\end{array}$ & $0 \mathrm{~W} / 3 \mathrm{~W} / 197 \mathrm{~W}$ \\
\hline
\end{tabular}

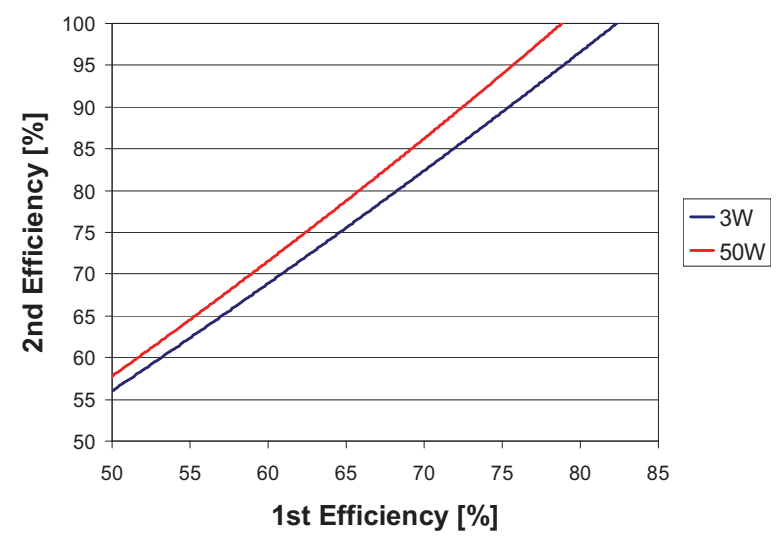

Figure 2. Minimum efficiency of additional $3 \mathrm{~W}$ and $50 \mathrm{~W}$ converters in order to save $30 \mathrm{~g}$ of fuel

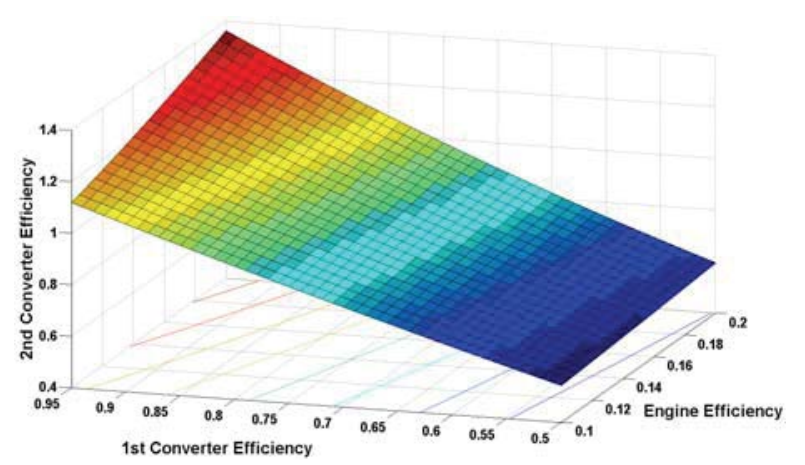

Figure 3. Minimum efficiency of additional $3 \mathrm{~W}$ converter in order to save $30 \mathrm{~g}$ of fuel

Using the last analysis it is important to see the influence of the engine's efficiency and to determine how big an impact it has. Figure 3 represents this dependency and as it can be seen, the higher the efficiency of the engine the higher efficiency by the second converter is needed in order to save $30 \mathrm{~g}$ of the total weight, and therefore, it gives stronger reasons to use just one converter.

\section{A. WEIGHT OF CONVERTERS}

After the number of converters has been selected, it is necessary to optimize their weight. Higher switching frequency results in a smaller inductor but the losses in the system will rise as well as the amount of the additional fuel. What is the optimal frequency for which the sum of the inductor weight and the weight of the additional fuel is minimal? In order to accomplish this task a special algorithm has been implemented. The total additional weight, the weight 
of the used inductor plus the weight of additional fuel, is estimated based on switching losses, and inductor geometry and losses. The input data for the algorithm are the system's voltage and power levels, a database for possible cores and MOSFET data. The algorithm varies the switching frequency and identifies a core in order to optimize total additional weight. The results are the core type and dimensions, number of turns needed to obtain certain inductance, system efficiency and optimal switching frequency.

In order to estimate MOSFET power losses a simple switching model is used [8,9]. The optimum switching frequency was not expected to be high, therefore more complicated models that include parasitic inductances [10] were not used. The MOSFET losses were decoupled into several loss mechanisms and calculated using the data from the data sheet for the selected MOSFET. The concerned loss mechanisms were the losses due to switching (voltage-current transitions), gate losses (due to parasitic gate capacitor), losses due to parasitic capacitance $C_{\text {oss }}$, losses due to resistance of the MOSFET, losses due to reverse recovery current. The losses inside the control chip were taken into account as well, because the chip is supplied by the converter's input voltage.

To estimate the power losses in the used inductor the losses due to DC resistance, skin effect and non-linearity of the core (hysteresis characteristics of the core) were considered. In a solution where all the inductor turns are placed close each to other, in order to use the smallest core, the proximity effect contributes to the total losses as well, however this is not modeled as part of the losses. The DC resistance is calculated quite simply using the information about the length of the copper wire that is needed for the inductor and the area of its cross section. [11]:

The AC resistance is estimated using the following equation

$$
R_{A C} \approx \frac{L \rho_{0}}{\pi \delta D}
$$

where $L$ is the total length of the used cable, $\rho_{0}$ is copper's resistivity, $\mathrm{D}$ is cable's diameter and $\delta$ is skin depth. The inductor current can be represented as an infinite sum of harmonics, and for each of these harmonics there is different $\mathrm{AC}$ resistance that is used. Since the first harmonic is the most dominant, the losses due to skin effect were estimated using the effective value of the current's first harmonic and using the $\mathrm{AC}$ resistance calculated at the switching frequency.

The losses due to the hysteresis characteristic of the used core were estimated using the Steinmetz equation [12]:

$$
P=V C f^{\alpha} B^{\beta}
$$

where $V$ is the volume of the selected core, $f$ is the switching frequency of the converter, $B$ is the amplitude of the excursion of magnetic inductance in the inductors core, and parameters $C$, $\alpha$ and $\beta$ are constants that depend on the core's material

All the power losses in the system must be compensated by the energy produced by the engine and additional fuel that is needed. The additional fuel is estimated using the information about the engine's efficiency and the heating value for the fuel.
In this way, we can find the total additional weight (the weight of fuel, copper wire and the used core) and try to find the switching frequency when this weight has its minimal value.

Figure 4 presents the result of one analysis in the case of a $200 \mathrm{~W}$ converter. The core database uses powder core data from Magnetics [12]. In Figure 4, from $50 \mathrm{kHz}$ to $150 \mathrm{kHz}$ the additional weight falls because the influence of inductor weight is more significant than the influence of the additional fuel needed to compensate the converter's losses. As the frequency rises, the converter's losses rise and the fuel weight has more influence than the inductor's weight. It can be seen that the optimal frequency is between $100 \mathrm{kHz}$ and $200 \mathrm{kHz}$. The steps in the curve are a consequence of the discrete weight values of the analyzed inductors. Table IV shows some possible solutions that could be used for the converter's inductor with its corresponding switching frequency.

\section{EXPERIMENTAL PERFORMANCE OF 20W AND 200W CONVERTERS}

In order to provide data for the optimization of the number of converters, and to verify the implemented algorithm, two prototypes were constructed. The first is a $20 \mathrm{~W}$ converter and the second is a $200 \mathrm{~W}$ converter. The $20 \mathrm{~W}$ converter is implemented with LM25576 step-down switching regulator and the $200 \mathrm{~W}$ converter as synchronous buck converter with LM5116 buck controller and SUD50N06-16P MOSFETs. The results of efficiency measurements are shown in Figure 5 and the photographs of the implemented converters in Figure 6. The switching frequency of the $200 \mathrm{~W}$ converter is $140 \mathrm{kHz}$. The main reasons to select these components were that the converter should have losses as low as possible and that should be highly reliable.

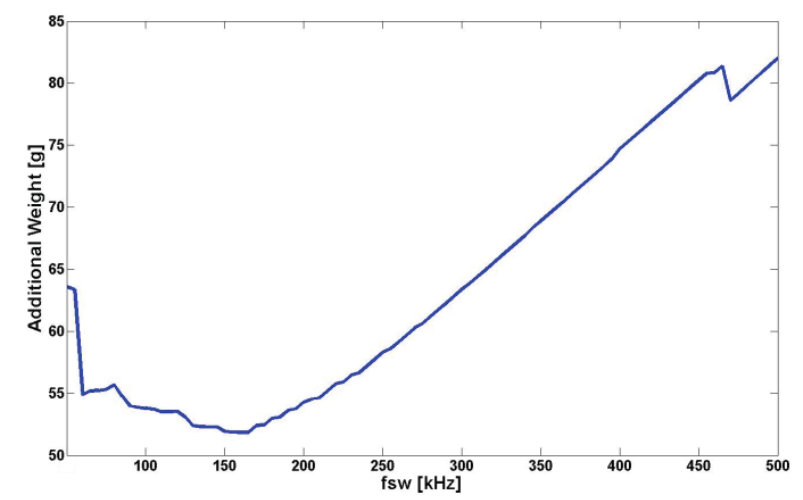

Figure 4. Additional weight of $200 \mathrm{~W}$ converter for different switching frequencies

TABLE IV

POSSIBLE SOLUTIONS FOR THE CONVERTER'S INDUCTOR

\begin{tabular}{|c|c|c|c|}
\hline $\begin{array}{c}\text { SWITCHING } \\
\text { FREQUENCY } \\
\text { (KHz) }\end{array}$ & $\begin{array}{c}\text { MATERIAL } \\
\text { TYPE }\end{array}$ & $\begin{array}{c}\text { TYPE OF } \\
\text { CORE }\end{array}$ & $\begin{array}{c}\text { NUMBER OF } \\
\text { TURNS }\end{array}$ \\
\hline 50 & MPP200 & 55307 & 30 \\
\hline 100 & HF60 & 58848 & 27 \\
\hline 150 & HF160 & 58118 & 19 \\
\hline
\end{tabular}




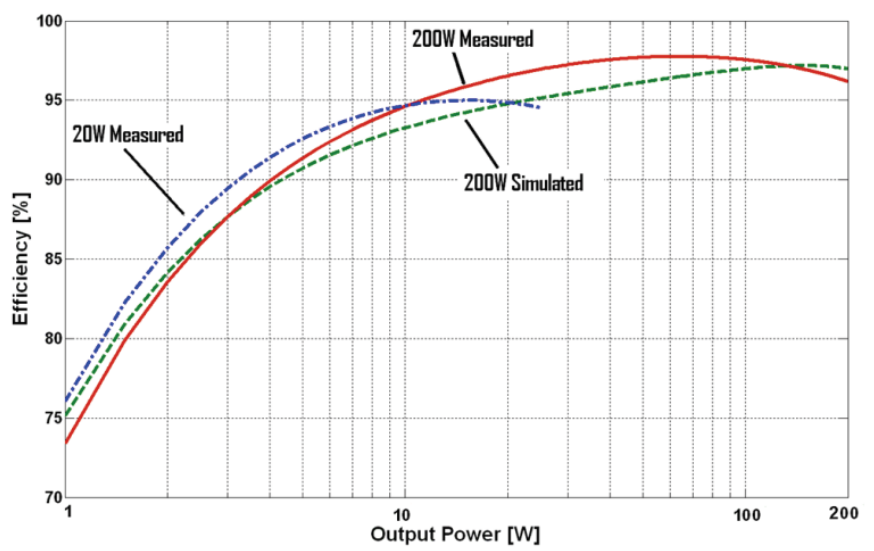

Figure 5. Efficiency of $20 \mathrm{~W}$ and $200 \mathrm{~W}$ converters for different output power

Therefore, single chip solution for the control stage with integrated power components (in the case of LM25576) or with additional power components (in the case of LM5116 and SUD50N06-16P) would be good solution. It is important to mention that these solutions are not the only one, and that other components could be selected as well.

The inductor core selection is based on the set of cores that are readily available and the implemented algorithm for determining the minimal additional weight. The main purpose of the measurements in the case of $20 \mathrm{~W}$ converter is to provide necessary data for the earlier analysis. As it can be seen, the loss model used follows the measured efficiency quite well and it is confirmed that the model is good enough to estimate the additional fuel weight and the optimal switching frequency range. From the results for the $200 \mathrm{~W}$ case it has been shown that this converter has efficiency of, approximately, $87 \%$ for $3 \mathrm{~W}$ load, $96 \%$ for $20 \mathrm{~W}$ load and $97 \%$ for $50 \mathrm{~W}$ load, and therefore this converter could be the solution. The $200 \mathrm{~W}$ converter fulfils the conditions that were set in the first analysis about the number of converters and the needed efficiency of the additional converter in order to have benefit of fuel savings. Putting any additional converter in the system would provide a small benefit from the point of view of total system weight.

The final result of this research is a prototype of complete system shown in Figure 7. The prototype is based on the conclusions and optimizations presented in [5] and in this paper. The total official competition weight of the system, including fuel and the housing, was 3989.6 grams.

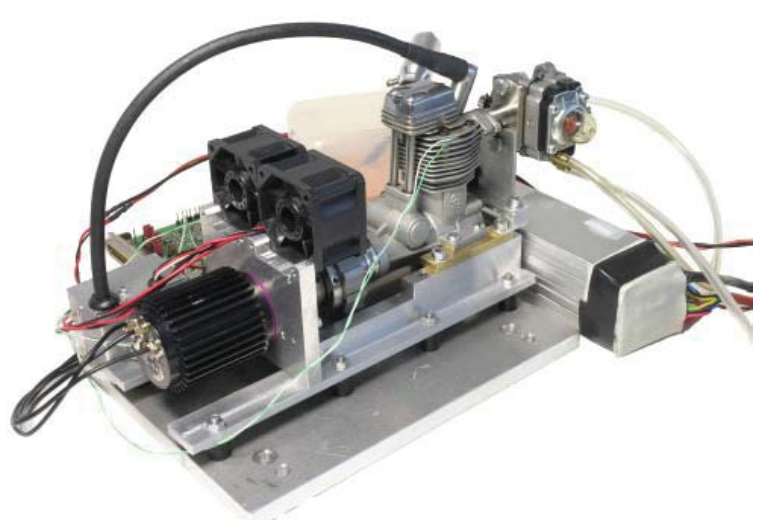

Figure 7. The individual parts of the realized prototype of Wearable Power System with total competition weight of 3989.6 grams. The system housing is not shown.

\section{CONCLUSION}

In this paper, an optimization of synchronous buck converter is presented where the total weight of a Wearable Power System is minimized for a given mission profile. Firstly, the optimum number of converters is determined and it has been shown that there is a correlation between the minimum efficiency of the additional converter in the system, and the weight savings that could be obtained by adding an additional converter. Based on the analysis, it has been shown that, as the result of the load profile, selecting only one $200 \mathrm{~W}$ converter is the optimal solution for the system. The second problem is to find the optimal switching frequency in order do minimize the weight of the inductor and the weight of additional fuel. Using the developed loss model for the system, it is concluded that the optimal switching frequency is in range between 100 to $200 \mathrm{kHz}$. Several core materials and core type have been proposed for the buck inductor. In order to verify the used models, two experimental converters have been constructed, and by measuring their efficiency, it has been shown that just one converter is the optimal solution for the Wearable Power System. Finally, the Wearable Power Supply has been constructed based on the optimization presented in this paper and on the optimization presented in [5]. The total system weight including fuel and housing was just less than the required $4 \mathrm{~kg}$.

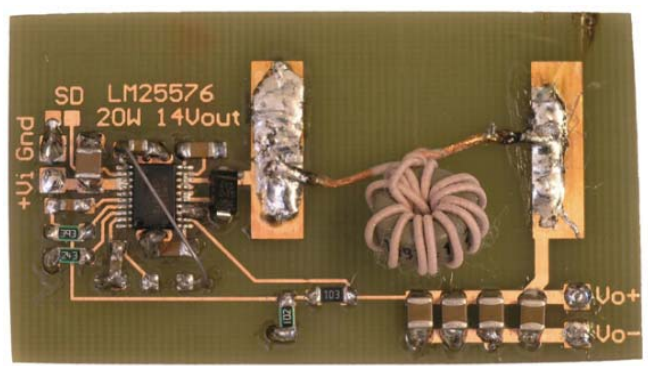

(a)

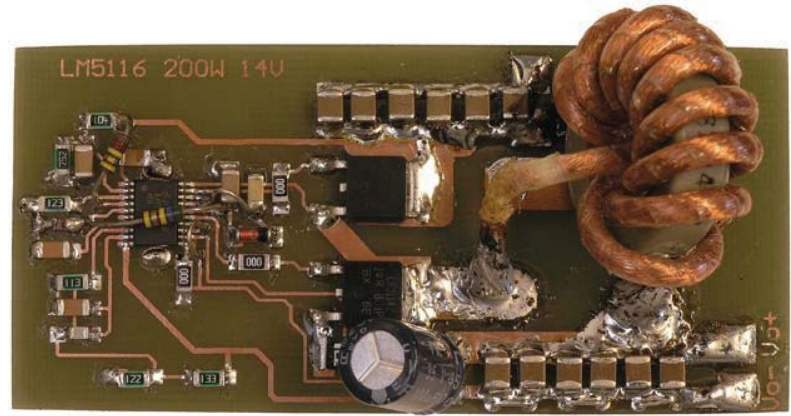

(b)

Figure 6. Photograph of implemented (a) $20 \mathrm{~W}(6 \mathrm{~cm} \times 2.5 \mathrm{~cm}, 12 \mathrm{~g})$ and (b) $200 \mathrm{~W}(7.5 \mathrm{~cm} \times 3.5 \mathrm{~cm}, 33 \mathrm{~g})$ converters 


\section{REFERENCES}

[1] US DOD Webpage: http://www.dod.mil/ddre/prize/topic.html

[2] D. Dunn-Rankin, E. Martins Leal, D. C. Walther, "Personal Power Systems", Progress in Energy and Combustion Science, vol. 31 pp. 422 $465,2005$.

[3] USA DOD, "Wearable Power Competition Rules", November 2007.

[4] USA DOD, "Wearable Power Prize Load Profiles for 48 hours", March 2008.

[5] I. Kovacevic, S.D. Round, J.W. Kolar and K. Boulouchos, "Optimization of a Wearable Power Supply", Proc. of Eleventh IEEE Workshop on Control and Modeling for Power Electronics, COMPEL 2008 - August 18-20, 2008

[6] R. Miftakhutdinov, J. Zbib, "Synchronous Buck Converter with Increased Efficiency", Proc. Of Applied Power Electronics Conference, APEC 2007 - Twenty Second Annual IEEE Feb. 25 2007-March 12007 Page(s):714 - 718

[7] B. Eckardt, M. März, "A 100kW Automotive Powertrain DC/DCConverter with $25 \mathrm{~kW} / \mathrm{dm} 3$ by using SiC," in Proc. PCIM, May 2006.

[8] AN-6005 Synchronous buck MOSFET loss calculations with Excel model, Jon Klein, Fairchild Semiconductor

[9] Power MOSFET Selection for Non-Isolated DC/DC Converters, International Rectifier, 2003.

[10] W. Eberle, Zhiliang Zhang; Yan-Fei Liu, P.C. Sen, "A simple analytical switching loss model for buck voltage regulators", Proc. Of Applied Power Electronics Conference, APEC 2008 - Twenty Third Annual IEEE 24-28 Feb. 2008 Page(s):36 - 42

[11] R. Erickson, D. Maksimovic, Fundamentals of Power Electronics, 2nd edition, Kluwer 2000.

[12] Core Design Manual and Catalog, Magnetics Inc Webpage: http://www.mag-inc.com/ 